\title{
Water Deficit Affects the Accumulation of Capsaicinoids in Fruits of Capsicum chinense Jacq.
}

\begin{abstract}
Nancy Ruiz-Lau, Fátima Medina-Lara, Yereni Minero-García, Enid Zamudio-Moreno, Adolfo Guzmán-Antonio, Ileana Echevarría-Machado, and Manuel Martínez-Estévez ${ }^{1}$ Unidad de Bioquímica y Biología Molecular de Plantas. Centro de Investigación Científica de Yucatán, Calle 43 \# 130, Col. Chuburná de Hidalgo, Mérida, Yucatán, México 97200
\end{abstract}

Additional index words. pungency, habanero pepper, capsaicin, dihydrocapsaicin, capsaicin synthase, water stress

\begin{abstract}
The pungency of chili peppers is conferred by compounds called capsaicinoids that are produced only in the fruits of the Capsicum genus. Accumulation of capsaicinoids in these fruits may be affected by environmental conditions such as water and nutrient stresses, although these effects may vary even among genotypes within a species. The Habanero pepper (Capsicum chinense Jacq.), grown in the Yucatán, is in especially high demand as a result of its unique flavor, aroma, and pungency and is the second most important commercial crop in the state after the tomato. Although the Habanero pepper is a significant economic resource for the region, few studies have investigated the effects of abiotic stresses on capsaicinoid production. In this study, the effects of water stress on plant growth, capsaicinoid accumulation, and capsaicin synthase activity were evaluated. Habanero pepper plants under water stress had a lower height, root dry weight, and root/ shoot relation than control plants, which were irrigated daily. However, fruit growth and production were unaffected by water stress. Capsaicin and dihydrocapsaicin concentrations increased in fruits of stressed plants compared with control plants, and this effect was correlated with fruit age. However, capsaicin synthase activity was reduced in response to water stress, and this effect depended on both stress severity and fruit age. These results provide new information on the regulation of capsaicinoid metabolism in response to abiotic stress from the fruit of a highly pungent chili pepper.
\end{abstract}

In Mexico, hot peppers represent both tradition and cultural identity. Hot peppers have been a predominant part of Mexican cuisine and culture for at least eight centuries. The appeal of hot peppers is mainly as a result of their pungency and flavor (ContrerasPadilla and Yahia, 1998). The Habanero pepper is a very important crop in Mexico, and its demand is increasing in both national and international markets. Habanero peppers produced on the Yucatán Peninsula are considered to be of superior quality to those grown in the rest of the world because of their long shelf life and pungency.

Capsaicin and other related compounds, commonly called capsaicinoids, are phenolic compounds characteristic of some fruits of the genus Capsicum (Bennett and Kirby, 1968). Capsaicin and dihydrocapsaicin are

Received for publication 14 Dec. 2010. Accepted for publication 18 Jan. 2011.

This research was supported by a Grant no. 24572/ 50625-Z and through a scholarship to N.R.-L (205076) and E.Z.M. (167384) by the Consejo Nacional de Ciencia y Tecnología (CONACyT) of Mexico.

We acknowledge the support of CDr. Teresita de Jesús Celis Aramburo with the ImageJ program.

${ }^{1}$ To whom reprint requests should be addressed; e-mail luismanh@cicy.mx. interactions (Iwai et al., 1979). Jurenitsch et al. (1979) found considerable differences in total capsaicinoids among cultivars grown in greenhouses, laboratory field studies, and regular plantations, highlighting the effects of environmental conditions on capsaicinoid content. However, the concentration of capsaicinoids varies depending on the different pepper cultivars examined (Govindarajan, 1986; Sung et al., 2005).

Estrada et al. (1999) reported that the amount of capsaicinoids, mainly capsaicin and dihydrocapsaicin, in Padrón pepper $(C$. annuиm L.) fruits from water-stressed plants was higher than in control plants, especially under low-water treatments. Overall, these results suggest that environmental conditions such as water stress have strong effects on capsaicinoid accumulation in Padrón pepper fruits as a result of competition between the biosynthesis of capsaicinoids and other phenylpropanoid metabolites.

The goal of this research was to evaluate the susceptibility of the Habanero pepper to water deficit stress and the effect of this abiotic stress on capsaicinoid (capsaicin and dihydrocapsaicin) production.

\section{Materials and Methods}

Plant materials and growth conditions. Capsicum chinense Jacq. cultivar Naranja seeds obtained from Seminis Vegetable Seeds, Inc. (Oxnard, CA) were germinated in peatmoss (Cosmo Peat, Cosmocell distributor). Seedlings were transplanted to plastic bags containing $6 \mathrm{~kg}$ of a net soil (Luvisol) and peatmoss $(2: 1, \mathrm{v} / \mathrm{v})$ mix when they reached 12 to $15 \mathrm{~cm}$ in height and presented five pairs of leaves. Plants were placed under controlled conditions in a greenhouse for $150 \mathrm{~d}$ and watered with $1 \mathrm{~L}$ of water per day until first anthesis.

Water deficit stress treatments. The water deficit stress treatments began at first anthesis (26 d after transplanting). One liter of water was applied either every seventh (T1) or ninth (T2) day. Plants receiving daily watering were used as controls. Three sets of eight plants were used in the experiments: T1, T2, and the control group.

Measurement of water potential in soil and leaves. Water potential of both soil and leaves was always determined in the morning using a WP4 water potential meter (Decagon Devices, Inc.). For soil water potential, a $10-\mathrm{mL}$ plastic pipette without a tip was used to take samples directly from a depth of $15 \mathrm{~cm}$. The first measurement of water potential was conducted after the fourth watering, and it was measured daily until the next water (in 7 or 9 d). For leaf water potential, samples were taken after the fourth and eighth waterings. Water potential was measured from leaves located at the plant apex zone.

The fourth watering occurred 54 and $62 \mathrm{~d}$ after transplants for T1 and T2, respectively, whereas the eighth watering occurred 82 and $98 \mathrm{~d}$ after transplants for $\mathrm{T} 1$ and $\mathrm{T} 2$, respectively. Eight repetitions were performed for each treatment. 
Labeling of flowers and harvest of fruits. Flowers were counted daily and marked to register the date of anthesis, and fruits were harvested at 25 and $45 \mathrm{~d}$ after anthesis (DAA). Morphological parameters such as size and fresh weight were measured. The placentas were extracted, frozen, and either kept at $-70{ }^{\circ} \mathrm{C}$ for protein extraction or lyophilized for subsequent capsaicinoid analysis.

Water deficit stress effect on shoot and root system development. To determine the water deficit stress effect on plant development, three plants per treatment were randomly selected at $120 \mathrm{~d}$ after transplantation, and height and fresh and dry weights of the shoots were measured. The root system was carefully removed from the bag to obtain the complete root. After several washes with water, length and fresh and dry root weights were measured. To determine the dry weight, samples were dried in an oven for $4 \mathrm{~d}$ at $60{ }^{\circ} \mathrm{C}$.

Capsaicinoid extraction and quantification. Capsaicinoids were extracted from Habanero pepper placentas using the protocol of Collins et al. (1995) with some modifications: $0.03 \mathrm{~g}$ of placenta dry weight was incubated with $10 \mathrm{~mL}$ of acetonitrile in a water bath at $80^{\circ} \mathrm{C}$ for $4 \mathrm{~h}$. Supernatant was collected after sample centrifugation for $20 \mathrm{~min}$ at $4420 \times \mathrm{g}$, and filtered using $0.45-\mu \mathrm{m}$ filters (Millex-HV polyvinyl difluoride).

As a result of the high concentration, samples had to be diluted five times with acetonitrile before capsaicinoid quantification by high-performance liquid chromatography (HPLC). Capsaicinoid quantification was carried out with a binary Perkin Elmer Series 200 HPLC with fluorescence detection. A reverse phase $\mathrm{C}_{18}$ Phenomenex column $(150 \mathrm{~mm} \times$ $4.6 \mathrm{~mm} ; 5-\mu \mathrm{m}$ particle sizes) and an Inertsil ODS $3-5-\mu \mathrm{m}$ column $(4.6 \times 50 \mathrm{~mm})$ were used. Capsaicinoid concentration was determined under the following conditions: a flow rate of $2 \mathrm{~mL} \cdot \mathrm{min}^{-1}$ for $8 \mathrm{~min}$, wavelengths between 280 and $338 \mathrm{~nm}$, and an isocratic mobile phase with $30 \%$ Solvent A (methanol $10 \%$, HPLC grade) and 70\% Solvent B (methanol 100\%, HPLC grade). The injection volume was $20 \mu \mathrm{L}$.

Stock solution $\left(10 \mathrm{mg} \cdot \mathrm{mL}^{-1}\right)$ of authentic standards of capsaicin and dihydrocapsaicin (Sigma-Aldrich) were used. Retention times for the authentic standards of capsaicin and dihydrocapsaicin were $4.2 \pm 0.2 \mathrm{~min}$ and $5.8 \pm 0.2 \mathrm{~min}$, respectively.

Extraction and enzymatic activity determination of capsaicin synthase. Total protein extraction and quantification from placentas of Habanero pepper fruits were carried out using the method proposed by Govindaswam and Ravishankar (2003). One gram fresh weight of placenta was homogenized with a $0.1 \mathrm{~mm}$ phosphate buffer, $\mathrm{pH} 6.8$, containing $5 \mathrm{~mm} 2-\beta$-mercaptoethanol. The extract was centrifuged at $23,708 \times g$, and the resulting supernatant (total extract) was used for protein and enzymatic activity measurement. Protein quantification was performed using the Bradford method (Bradford, 1976) with a Bio-Rad protein assay kit and bovine serum albumin as the standard.
For the enzymatic activity assay, the method proposed by Govindaswam and Ravishankar (2003) was used. The reaction $0.5 \mathrm{mmol} \cdot \mathrm{L}^{-1}$ phosphate (pH 6.8), $1 \mu \mathrm{mol} \cdot \mathrm{L}^{-1}$ $\mathrm{MgCl}_{2}, 1 \mu \mathrm{mol} \cdot \mathrm{L}^{-1}$ ATP, $5 \mu \mathrm{mol} \cdot \mathrm{L}^{-1}$ vanillylacid, and protein extract ( $62 \mu \mathrm{g}$ of protein). Both a reaction mixture without protein and another with a protein extract heated to $95^{\circ} \mathrm{C}$ for $15 \mathrm{~min}$ were used as controls. The reaction was carried out at $37{ }^{\circ} \mathrm{C}$ for $2 \mathrm{~h}$ and stopped with $98 \%$ cold ethanol. Formed capsaicin was extracted four times successively with $500 \mu \mathrm{L}$ of ethyl acetate. After evaporation, the samples were re-suspended in 500 $\mu \mathrm{L}$ of HPLC-grade absolute ethanol and filtered using $0.45-\mu \mathrm{m}$ Millex-HV polyvinyl difluoride filters. Quantification was performed using HPLC under similar conditions to those used to quantify the capsaicinoids in fruit. The specific activity of capsaicin synthase is expressed as micromoles per minute of capsaicin formed per milligram of protein $\left(\mu \mathrm{mol} \cdot \mathrm{min}^{-1}\right.$ per $\mathrm{mg}$ protein).

Statistical analysis. The data were analyzed with a one-way analysis of variance (Sigma Stat Version 3.1). The means of treatments were compared with Duncan's multiple range test $(P=0.05)$.

\section{Results and Discussion}

Habanero pepper plants were in severe water deficit stress. One of two water regimes was imposed on Habanero pepper plants at first anthesis: irrigation every 7 (T1) or 9 (T2) d. To determine whether the plants were in water stress, water potential in both the soil and leaves was measured.

Soil water potential was evaluated throughout the period from irrigation to before rewatering. Both curves were made after the fourth watering in each water treatment. In the mixture $(500 \mu \mathrm{L})$ contained the following: amine hydrochloride, $5 \mu \mathrm{mol} \cdot \mathrm{L}^{-1}$ nonanoic

case of the control plants, subjected to daily watering, the water potential in the soil was $0 \mathrm{MPa}$.

During the treatments, soil water potential became increasingly negative, measuring significantly lower from the fourth and third day after irrigation for $\mathrm{T} 1$ and $\mathrm{T} 2$, respectively (Fig. 1). For plants watered every $7 \mathrm{~d}$, the water potential of the soil reached a value of $-2.09 \mathrm{MPa}$ on the seventh day (Fig. 1A), whereas for plants watered every $9 \mathrm{~d}$, the water potential was $-3.13 \mathrm{MPa}$ on the ninth day (Fig. 1B).

Hsiao (1973) proposed an arbitrary scale for establishing the level of water stress or degree of drought. He said that higher water potential up to $-1.5 \mathrm{MPa}$ in the soil corresponds to levels of severe stress. By comparing the values of water potential obtained in our treatments with those proposed by Hsiao (1973), we can say that the Habanero pepper plants in both treatments were under severe water stress beginning on the fifth day without irrigation.

Leaf water potential was significantly lower in plants under water stress treatments compared with control plants, which had a leaf water potential of $\approx-0.57 \mathrm{MPa}$ (Table 1 ). The lowest water potential, $-2.10 \mathrm{MPa}$, was found in T1 plants at the eighth irrigation. In contrast, T2 plants showed a potential of -1.27 $\mathrm{MPa}$ at the eighth irrigation (Table 1). T1 plants always had more developed leaves than T2 plants (data not shown), suggesting an increase in the evapotranspiration rate.

It can be inferred that both irrigation treatments resulted in a decrease in the water potential of the Habanero pepper plants, causing water stress.

As the moisture content in the soil decreases, it is difficult for plants to absorb water, ultimately reaching a level from which they can no longer recover. This level is called the point of permanent withering. In this study,

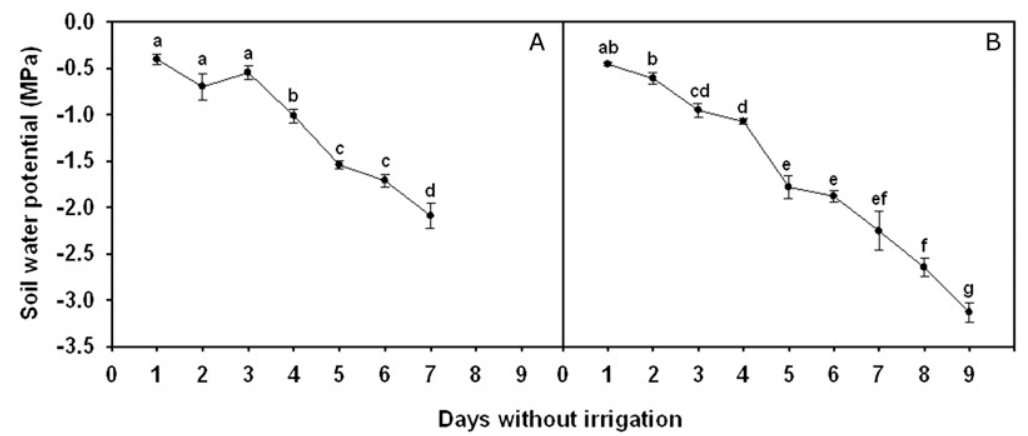

Fig. 1. Time course curves of soil water potentials from water stress treatments. (A) Watering every $7 \mathrm{~d}$ (Tukey $P<0.001 ; \mathrm{n}=5$ ). (B) Watering every $9 \mathrm{~d}$ (Tukey $P=0.001 ; \mathrm{n}=5$ ). Data are means of eight repetitions, and vertical bars represent SE of means. Different letters represent significant differences.

Table 1. Leaves water potential in Habanero pepper plants submitted to water stress. ${ }^{\mathrm{z}}$

\begin{tabular}{|c|c|c|c|c|}
\hline \multicolumn{5}{|c|}{ Osmotic potential (MPa) } \\
\hline Irrigation number & \multicolumn{2}{|c|}{$\mathrm{T} 1$} & \multicolumn{2}{|c|}{$\mathrm{T} 2$} \\
\hline after first anthesis & Fourth & Eighth & Fourth & Eighth \\
\hline Control & $-0.57 \pm 0.01$ & $-0.57 \pm 0.02$ & $-0.57 \pm 0.01$ & $-0.57 \pm 0.02$ \\
\hline Treatments & $-1.22 \pm 0.19$ & $-2.1 \pm 0.35$ & $-1.1 \pm 0.28$ & $-1.27 \pm 0.21$ \\
\hline
\end{tabular}

${ }^{\mathrm{z}}$ Data are means of eight repetitions $\pm \mathrm{SE}$. 
despite the very negative recorded values of water potential, the plants recovered fully and never reached the point of permanent withering (Supplemental Fig. 1).

Water deficit stress affected plant development and fruit production. Both growth and total dry matter accumulation in plants are seriously affected by a lack of water in the soil (Rogers et al., 1996). To determine whether water stress had a negative effect on the development of Habanero pepper plants, shoot height, root length, and fresh and dry weights of both parts were measured in plants $120 \mathrm{~d}$ after transplant.

Plants under T1 did not show significantly reduced dry or fresh weight of shoot when compared with control plants subjected to daily watering (Fig. 2A). However, spacing irrigation to $9 \mathrm{~d}$ (T2) significantly decreased the fresh weight but not dry weight of this plant part (Fig. 2A). Both stress conditions significantly decreased plant height.
The development of the root system was also modified by water stress (Fig. 2B). Treatment $\mathrm{T} 1$ did not affect fresh weight or root total length, whereas T2 significantly reduced the root fresh weight. The decrease in the fresh weight could be the result of water loss suffered by plants exposed to water stress or the reduction in water uptake under this treatment. Root dry weight was markedly reduced in both stress treatments (Fig. 2B).

Many plants redistribute photoassimilate toward the shoot or root system to be able to tolerate adverse environments (Casierra et al., 2006; Rogers et al., 1996). The ratio of the dry weight of root to aerial part is an assessment that allows us to infer whether there is photoassimilate redistribution. This relation was calculated in the Habanero pepper plants subjected to water stress (Fig. 2C). The values of the root to aerial part dry weight ratios were significantly different between the control and treatments. Both $\mathrm{T} 1$ and $\mathrm{T} 2$ treatments
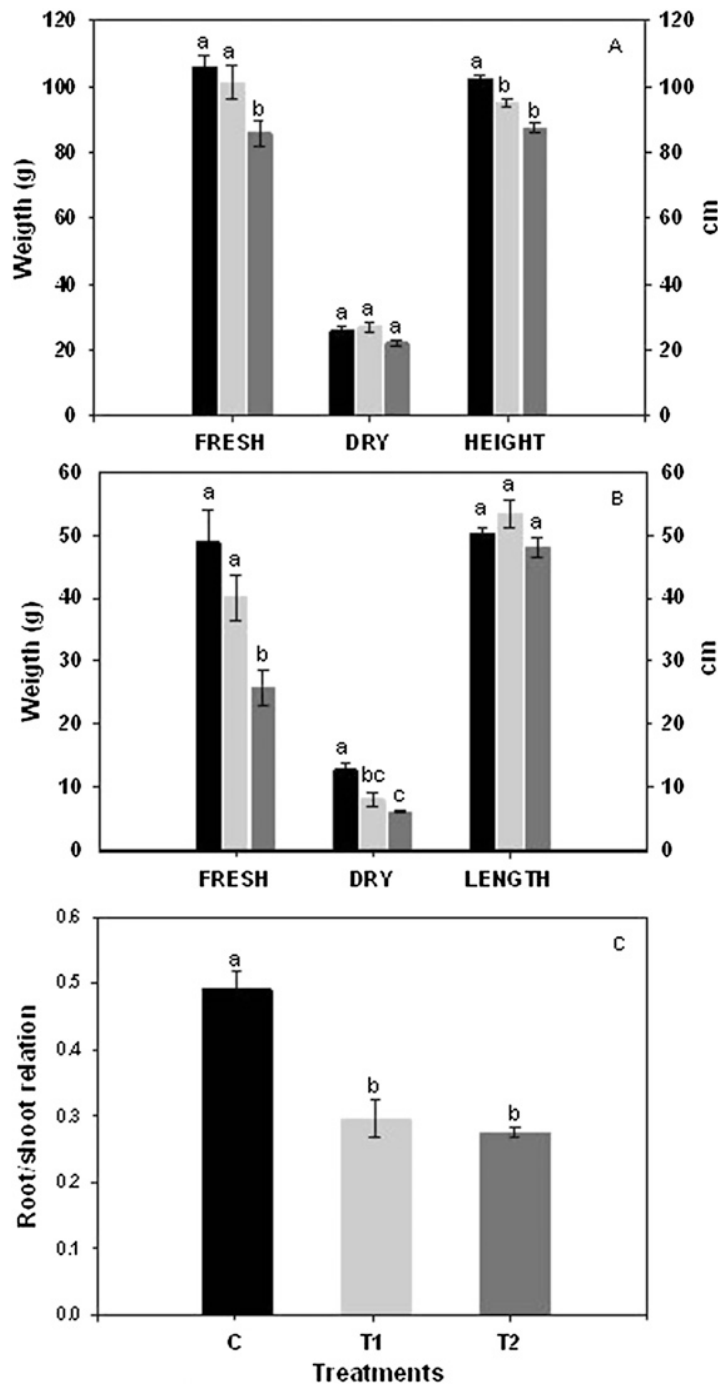

Fig. 2. (A) Fresh weight (Tukey $P<0.034 ; \mathrm{n}=3$ ), dry weight ( $\mathrm{n}=3$ ), and height (Tukey $P<0.001 ; \mathrm{n}=3$ ) of aerial part; (B) fresh weight (Tukey $P<0.018 ; \mathrm{n}=3$ ), dry weight $(P=0.004 ; \mathrm{n}=3)$, and length of radical system; and $(\mathbf{C})$ dry weights of the aerial part and the root relationship (Tukey $P<0.001 ; \mathrm{n}=3$ ). The same letters indicate equal means $($ bars $= \pm \mathrm{SE}$ ). Data are means of three repetitions and vertical bars represent SE of means. Different letters represent significant differences. (ロ) Daily watering

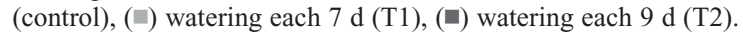

significantly reduced this relation. This means that under conditions of water stress, Habanero pepper plants sent less photoassimilate to roots, and thus the production of aboveground biomass was unaffected. In control plants, for every gram of dry weight produced, there was $2 \mathrm{~g}$ of aboveground matter, whereas in treated plants, there was $3.33 \mathrm{~g}$ dry weight of aboveground matter per gram of root matter (Fig. 2C).

Flower production was monitored and recorded according to the day of anthesis. Fruits were collected twice: at 25 and 45 DAA, and morphological parameters such as size and fresh weight were measured. Maximum production of flowers was recorded in plants receiving daily watering (control), reaching $\approx 183$ total flowers per plant. However, there were not significant differences between treatments and control (Table 2). An analysis of fruit number per plant also found no differences between the treatments and the control (Table 2). Therefore, our results showed that under water stress conditions, production of flowers and fruits of Habanero pepper plants was unaffected significantly. Jaimez et al. (2000) evaluated the effect of water deficit on flowering dynamics and fruit production in $C$. chinense Jacq. from a Venezuela semitropical region; they observed a reduction in the number of flowers and a delay in occurrence of maximum flowering in response to water stress. In this experiment, the plants were subjected to several water regimes during 3 consecutive years in a semiarid region with a mean annual temperature of $11^{\circ} \mathrm{C}$, mean annual precipitation of 469 $\mathrm{mm} /$ year, and a water potential value in the soil between -1.5 and $-1.9 \mathrm{MPa}$, depending of the number of days after transplant.

It is important to note that fruit set was low with $\approx 90 \%$ flower and fruit abortion. This behavior has been reported previously for C. chinense (Medina-Lara et al., 2008) and C. annuum (Bakker, 1989; Marcelis et al., 2004) in greenhouse conditions.

The quality of the Habanero pepper is determined by the appearance and weight of the fruit; firmness and color are also important. We measured both fruit and placenta fresh weights. $\mathrm{T} 1$ and $\mathrm{T} 2 \mathrm{had}$ a transient effect on the fruit fresh weight; a reduction in this parameter was observed in fruits from stressed plants at 25 DAA compared with control plants, but at 45 DAA, no difference in fresh weight was observed (Table 2). Water stress did not affect the placenta fresh weight in Habanero pepper fruits (Table 2).

Water deficit stress increased capsaicin and dihydrocapsaicin concentrations in $\mathrm{Ha}$ banero pepper fruits. Pungency of the fruit of the genus Capsicum is a characteristic that results from the interaction between the phenotype and the environment (ContrerasPadilla and Yahia, 1998; Estrada et al., 1997; Johnson and Decoteau, 1996; Sung et al., 2005). Jurenitsch et al. (1979) reported differences in total capsaicinoids among plants grown in greenhouses, in laboratory conditions. and in normal planting conditions, highlighting the effect of environmental conditions 
on the capsaicin content. Another important characteristic that influences capsaicinoids content is fruit age, because these compounds are accumulated in different ways throughout the plant's development.

To study the effect of water stress on capsaicinoid concentration in Habanero pepper fruits, capsaicin and dihydrocapsaicin concentration was evaluated from different parts of the fruit: seed, pericarp, and placenta. These evaluations were performed in 25 and 45 DAA fruits.

Water deficit stress significantly increased capsaicin and dihydrocapsaicin concentrations in both seed and pericarp from 25 and 45 DAA fruits (Fig. 3A-B). The effect of stress on capsaicinoid concentration in seeds from 25 DAA fruits was dependent on stress severity, whereas in 45 DAA fruits, the effect was higher compared with 25 DAA fruits, and this increase was independent of stress severity (Fig. 3A). A higher stimulation of jected to stresses compared with 25 DAA fruits also was observed for capsaicinoid concentrations in the pericarp. The effect on the capsaicin production in 45 DAA fruits sub-

pericarp was always independent of stress treatment for fruits of both ages (Fig. 3B). Capsaicin and dihydrocapsaicin were found to be at minimal concentrations in seeds and in the pericarp, so it is assumed that the presence of these compounds in these parts of the fruit is the result of contamination from their proximity to the placenta. Some reports mention that the sites of synthesis and accumulation of capsaicinoids are the epidermal cells of the placenta (Curry et al., 1999; Stewart et al., 2007).

Both water stress treatments led to a significant increase in the concentration of capsaicin [an increase of $16 \mathrm{mg} \cdot \mathrm{g}^{-1}$ dry weight (DW) with respect to control] and dihydrocapsaicin (19 $\mathrm{mg} \cdot \mathrm{g}^{-1} \mathrm{DW}$ increase with respect to control) in the placenta of 45 DAA fruits but did not significantly modify the capsaicinoid concentration in 25 DAA fruits (Fig. 3C). It is important to note that the capsaicinoid levels in control plants were similar for both 25 and 45 DAA fruits. In general, capsaicinoid content was highest in the placenta followed by the pericarp and seed. In addition, the concentration of capsaicin was

Table 2. Numbers of flowers, fruits, and comparison between fresh weights of fruits and placentas at 25 and 45 DAA from Habanero pepper plants under different water stress conditions. ${ }^{\mathrm{z}}$

\begin{tabular}{lrrr}
\hline & \multicolumn{1}{c}{ Control } & T1 & T2 \\
\hline Flowers number per plant & $183.50 \pm 17.7$ & $144.67 \pm 5.93$ & $135.33 \pm 13.57$ \\
Fruits number per plant & $15.67 \pm 2.14$ & $11.83 \pm 1.58$ & $10.33 \pm 2.2$ \\
Fruit fresh weight $(\mathrm{g})$ & $5.03 \pm 0.24$ & $4.14 \pm 0.27$ & $3.90 \pm 0.29$ \\
25 DAA & $5.42 \pm 0.29$ & $4.93 \pm 0.33$ & $5.19 \pm 0.34$ \\
45 DAA & & & \\
Placenta fresh weight $(\mathrm{g})$ & $0.59 \pm 0.05$ & $0.51 \pm 0.03$ & $0.50 \pm 0.07$ \\
25 DAA & $0.45 \pm 0.06$ & $0.47 \pm 0.06$ & $0.50 \pm 0.06$ \\
45 DAA & & & \\
2 & & &
\end{tabular}

${ }^{\mathrm{z} D a i l y}$ watering (control), watering every $7 \mathrm{~d}(\mathrm{~T} 1)$ and watering every $9 \mathrm{~d}(\mathrm{~T} 2)$ (Tukey $P=0.022, \mathrm{n}=6$ ). $\mathrm{DAA}=$ days after anthesis. greater than that of dihydrocapsaicin in all cases.

Within the species Capsicum annuum L. var. annuum, there are cultivars whose content of capsaicinoids ranges from $0.07 \%$ to $1.5 \%$ of the DW of the fruit without seeds (Jurenitsch et al., 1979). Estrada et al. (1997) reported that capsaicin content in Capsicum annuиm L. var. Padrón was higher in the placenta and in the septum, representing $2.5 \%$ of fruit dry matter, whereas the average content was $0.6 \%, 0.7 \%$, and $0.03 \%$ from fruit, seed, and pericarp, respectively. Our study showed that the placenta of the Habanero pepper contains $8.04 \%$ and $4.57 \%$ of fruit dry matter of capsaicin and dihydrocapsaicin, respectively, in 45 DAA fruits from T2 plants. These are superior values to detect for $C$. annuиm.

Capsaicin synthase activity was affected by water deficit stress. Capsaicin is an alkaloid found only in the spicy fruit of the genus Capsicum. This compound is synthesized by capsaicin synthase activity through the condensation of vanillylamine (phenylpropanoid pathway) and the acid 8-methyl-6-nonen (fatty acid pathway). Immunolocalization studies confirm that capsaicin synthase enzyme is specifically localized in the placenta of the fruit (Narasimha et al., 2006).

Because the placenta is the principal organ of accumulation and synthesis of capsaicinoids, it was used to quantify the capsaicin synthase activity from Habanero peppers subjected to water stress. The placentas were extracted from 25 and 45 DAA fruits as in the quantification of capsaicinoid levels. There is no zero time, because the enzymatic activity was measured in the placenta of fruits, and at zero time, there are no fruits; therefore, there are no placentas.
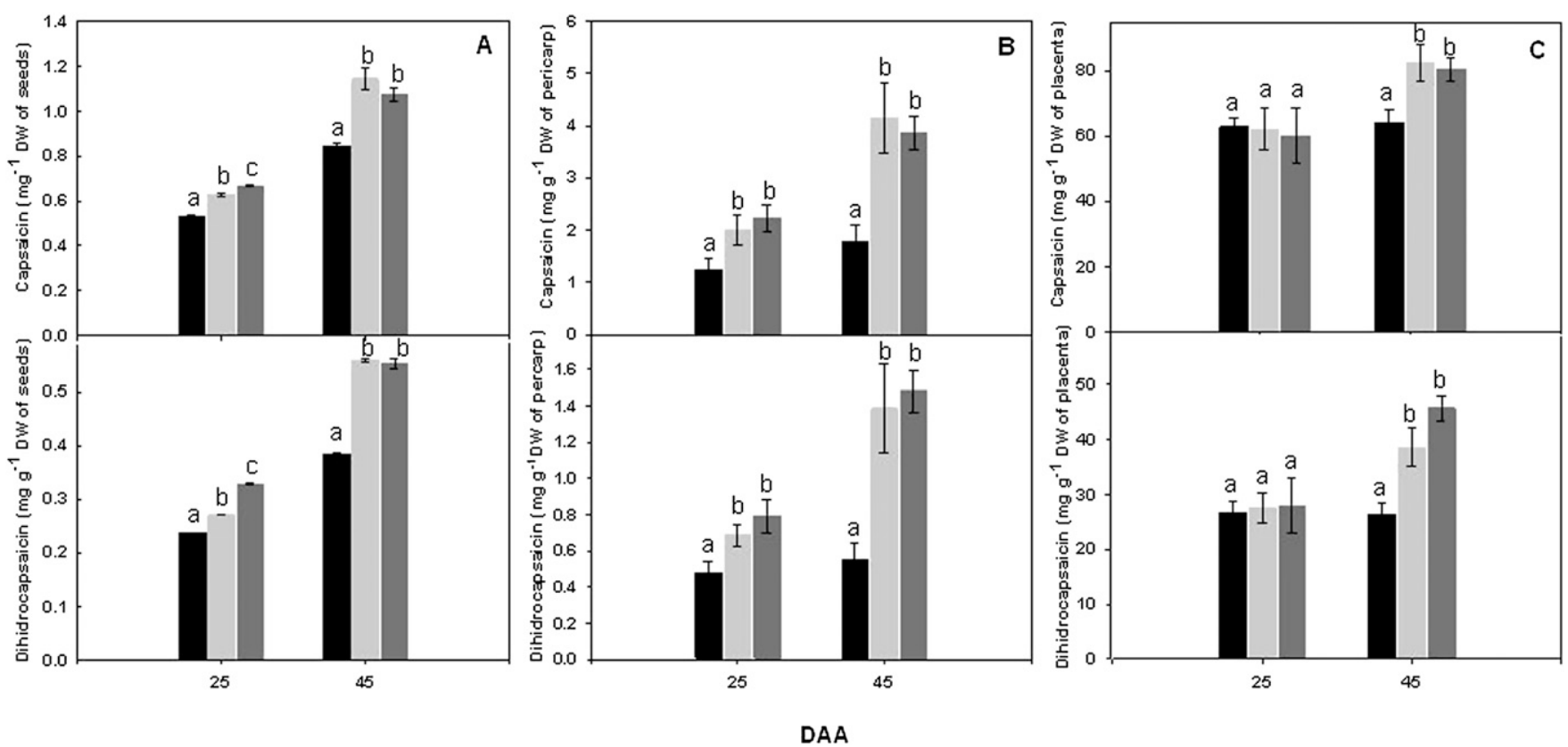

Fig. 3. Effects of water stress on capsaicin (top panel) and dihydrocapsaicin (bottom panel) contents in (A) seeds, (B) pericarp, and (C) placentas from Habanero pepper plants at both $25 \mathrm{~d}$ after anthesis (DAA) (Tukey $P<0.001 ; \mathrm{n}=3$ ) and 45 DAA (Tukey $P<0.002 ; \mathrm{n}=3$ ). Equal means (bars $= \pm \mathrm{SE}$ ). Data are means of three repetitions and vertical bars represent SE of means. Different letters represent significant differences. (匹) Daily watering (control), ( $\square)$ watering each $7 \mathrm{~d}(\mathrm{~T} 1)$, ( $\square)$ watering each $9 \mathrm{~d}(\mathrm{~T} 2)$. 
The effect of water stress on capsaicin synthase activity depended on fruit age. An increase in the specific activity of capsaicin synthase during fruit ripening was observed from control plants subjected to daily watering (Fig. 4). In the placentas of the 25 DAA fruits, enzyme activity was significantly increased by limiting irrigation to every $9 \mathrm{~d}$, whereas activity in plants submitted to irrigation every $7 \mathrm{~d}$ remained similar to that of the control plants. Conversely, 45 DAA fruits showed a decrease in capsaicin synthase activity in water-stressed plants, ultimately reaching undetectable values in plants irrigated every 9 d (Fig. 4).

The concentration of a compound in the cell depends on the relationship between synthesis and degradation. The data on capsaicin concentration in placentas of the 25 DAA fruit (Fig. 3) suggest that synthesis and degradation processes were similar in both $\mathrm{T} 1$ and T2 treatments and the control. However, we obtained an increase in capsaicin synthase activity in T2 plants compared with the control (Fig. 4), which cannot be explained by the concentration of capsaicin in the placenta during synthesis.

The capsaicin concentration in placentas of 45 DAA fruit indicates a capsaicin accumulation in response to water deficit stress (Fig. 3). This characteristic suggests that the process of synthesis exceeds degradation. However, capsaicin synthase activity was significantly reduced in the placentas of fruits of this age in plants subjected to water stress (Fig. 4). Therefore, the capsaicin accumulation in stressed fruit can be explained only through a reduction in its degradation.

Fujikawe et al. (1980) and Iwai et al. (1979) have suggested that peroxidases are involved in the degradation of capsaicinoids. Contreras-Padilla and Yahia (1998) also found that the most likely cause of capsaicinoid loss at the start of fruit senescence is peroxidase activity. They reported a peak of capsaicinoid accumulation in $C$. chinense fruits between 45 and 50 DAA and maximum peroxidase activity at $60 \mathrm{DAA}$, after which there is a drastic decrease in capsaicinoids. Sung et al. (2005) found that peroxidase activity is lower in fruits of $C$. annuum $\mathrm{L}$. var. annuum (Beauty Zest) exposed to a water deficit 50 DAA. Thus, the oxidation of capsaicin could be reduced when plants experience water stress.

Our results show that peroxidases present in Habanero pepper fruits has lower activity when plants are subjected to water deficit by 7 (T1) and 9 (T2) d (Supplemental Fig. 2). These results indicate that the degradation of capsaicin in these fruits could be a response to water deficit stress conditions and needs further investigation to understand better how this process is occurring. Currently, we are characterizing the peroxidases present in Habanero pepper fruits and their roles in regulating capsaicin levels in response to water stress.

Also, our results suggest too that capsaicin synthase is regulated in response to water deficit stress. These results are novel because there are few reports on capsaicin synthase activity (Govindaswam and Ravishankarar, 2003; Narasimha et al., 2006; Sung et al., 2005) and none for the Habanero pepper. Narasimha et al. (2006) evaluated the activity of this enzyme from 28 DAA fruits of three genotypes of Capsicum frutescens with different levels of pungency (high, medium, and low), and their results indicate a high correlation between the activities of this enzyme and fruit pungency. Sung et al. (2005) reported that water stress effect on capsaicin synthase activity from $C$. annuum $\mathrm{L}$. var. annuum depended on age of the fruit.

The results presented in this article provide new data on the regulation of metabolism of capsaicinoids in response to water stress in the fruits of a highly pungent chili, the Habanero. The role of these compounds and the importance of regulating their levels in fruits from plants under abiotic stress must be addressed in future works.

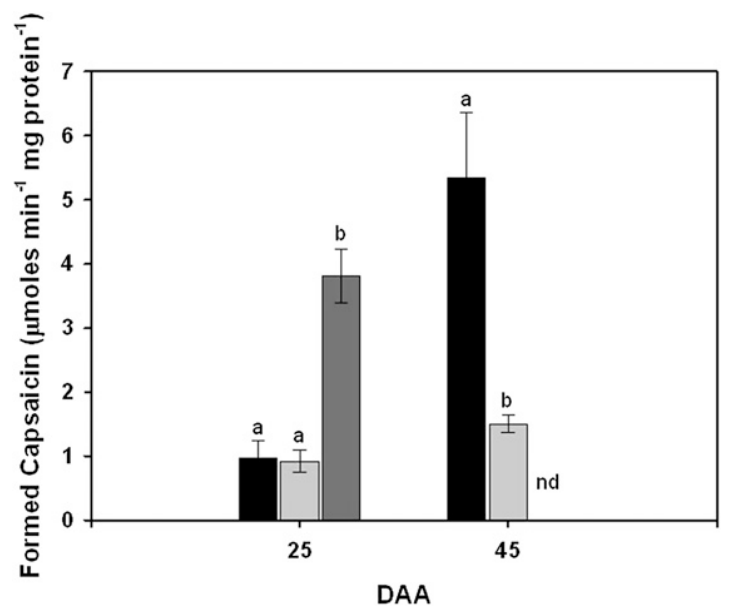

Fig. 4. Water stress effect on capsaicin synthase activity in placentas from fruits $25 \mathrm{~d}$ after anthesis (DAA) (Tukey $P<0.001 ; \mathrm{n}=3$ ) and 45 DAA (Tukey $P<0.021 ; \mathrm{n}=3$ ). The same letters indicate equal means $($ bars $= \pm \mathrm{SE}) . \mathrm{ND}=$ none detected. Data are means of three repetitions and vertical bars represent SE of

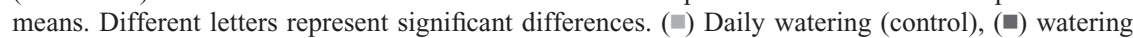
each $7 \mathrm{~d}(\mathrm{~T} 1)$, (-) watering each $9 \mathrm{~d}(\mathrm{~T} 2)$.

\section{Literature Cited}

Bakker, J.C. 1989. The effects of air humidity on flowering, fruit set, seed set and fruit growth of glasshouse sweet pepper (Capsicum annuиm L.). Sci. Hort. 40:1-8.

Bennett, D.J. and G.W. Kirby. 1968. Constitution and biosynthesis of capsaicin. J. Chem. Soc. C: Organic 442-446.

Bernal, M.A., F. Merino de Cáceres, and A. Ros Barceló. 1994. Histochemical localization of peroxidase in capsicum fruits. Lebensm-Wiss u. Technol. 27:197-198.

Bosland, P.W. 1992. Chiles: A diverse crop. HortTechnology 2:6-10.

Bradford, M.M. 1976. A rapid and sensitive method for the quantitation of microgram quantities of protein utilizing the principle of protein dyebinding. Ann. Biochem. 72:248-254.

Casierra, P.F., W.A. Pérez, and F. Portilla. 2006. Water relations and dry matter partitioning of $\mathrm{NaCl}$ stressed Furcraea species (Furcraea sp. Vent.). Agronomía Colombiana 24:280 289.

Collins, M., L. Wasmund, and P. Bosland. 1995. Improved method for quantifying capsaicinoids in Capsicum using high-performance liquid chromatography. HortScience 30:137-139.

Contreras-Padilla, M. and E.M. Yahia. 1998 Changes in capsaicinoids during development, maturation and senescence of chili pepper and relation with peroxidase activity. J. Agr. Food Chem. 46:2075-2079.

Curry, J., M. Aluru, M. Mendoza, J. Nevarez, M. Melendrez, and M.A. O'Connell. 1999. Transcripts for possible capsaicinoid biosynthetic genes are differentially accumulated in pungent and non-pungent Capsicum spp. Plant Sci. 148: $47-57$.

Estrada, A.B., F. Pomar, J. Díaz, F. Merino, and A. Bernal. 1997. Evolution of capsaicinoids in Capsicum annuum L. var. annuum cv. Padrón fruit at different growth stages. Capsicum and Eggplant Newsletter 16:60-63.

Estrada, A.B., F. Pomar, J. Díaz, F. Merino, and A. Bernal. 1999. Pungency level in fruits of Padrón pepper with different water supply. Sci. Hort. 81:385-396.

Fujikawe, H., T. Susuki, and K. Iwa. 1980. Intracellular localization of capsaicin and its analogues in Capsicum fruit. The vacuole as the intracellular accumulation site of capsaicinoid in the protoplast of Capsicum fruit. Plant Cell Physiol. 21:1023-1030.

Govindarajan, V.S. 1986. Capsicum production, technology, chemistry, and quality. Part II. Processed products, standards, world production and trade. CRC Crit. Rev. Food Sci. Nutr. 24:207-288.

Govindarajan, V.S. and M.N. Sathyanarayana. 1991. Capsicum production, technology, chemistry, and quality. Part V. Impact on physiology, pharmacology, nutrition, and metabolism; structure, pungency, pain, and desensitization sequences. CRC Crit. Rev. Food Sci. Nutr. 29: 435-473.

Govindaswam, S. and G.A. Ravishankar. 2003. Putrescine facilitated enhancement of capsaicin production in cell suspension cultures of Capsicum frutescens. J. Plant Physiol. 160:339346.

Hall, R.D., M.A. Holden, and M.M. Yeoman. 1987. The accumulation of phenylpropanoid and capsaicinoid compounds in cell cultures and whole fruit of the chilli pepper, Capsicum frutescens Mill. Plant Cell Tiss. Org. 8:163176.

Hsiao, T.C. 1973. Plant response to water stress. Annu. Rev. Plant Physiol. 24:519-570. 
Iwai, K., T. Suzuki, and H. Fujiwake. 1979. Formation and accumulation of pungent principle of hot pepper fruits, capsaicin and its analogues, in Capsicum annuum L. var. annuum cv. Karayatsubusa at different growth stages after flowering. Agr. Biol. Chem. 43: 2493-2498.

Jaimez, R.E., O. Vielma, F. Rade, and C. GarcíaNuñez. 2000. Effect of water deficit on the dynamics of flowering and fruit production in Capsicum chinese Jacq in a tropical semiarid region of Venezuela. J. Agron. Crop Sci. 185: 113-119.

Johnson, D.C. and D.R. Decoteau. 1996. Nitrogen and potassium fertility affects Jalapeño pepper plant growth, pod yield, and pungency. HortScience 31:1119-1123.

Jurenitsch, J., M. David, F. Herescht, and W. Kubelka. 1979. Detection and identification of new pungent compounds in Capsicum fruits. Planta Med. 36:61-65.
Kosuge, S. and M. Furata. 1970. Studies on the pungent principle of Capsicum. Part XIV: Chemical constitution of the pungent principle. Agr. Biol. Chem. 34:248-256.

Marcelis, M., E. Heuvelink, L. Baan Hofman-Eijer, J. Den Bakker, and L. Xue. 2004. Flower and fruit abortion in sweet pepper in relation to source and sink strength. J. Expt. Bot. 55:2261-2268.

Medina-Lara, F., I. Echevarría-Machado, R. PachecoArjona, N. Ruiz-Lau, A. Guzmán-Antonio, and M. Martínez Estévez. 2008. Influence of nitrogen and potassium fertilization on fruiting and Capsicum content in Habanero pepper ( Capsicum chinense Jacq.). HortScience 43:15491554.

Narasimha, P.B.C., V. Kumar, H.B. Gururaj, R. Parimalan, P. Giridhar, and G.A. Ravishankar. 2006. Characterization of capsaicin synthase and identification of its gene (csy1) for pungency factor capsaicin in pepper (Capsicum sp.). Proc. Natl. Acad. Sci. USA 103:13315-13320.
Rogers, H.H., S.A. Prior, G.B. Runion, and R.J. Mitchell. 1996. Root to shoot ratio of crops as influenced by $\mathrm{CO}_{2}$. Plant Soil 187:229-248.

Salgado-Garciglia, R. and N. Ochoa-Alejo. 1990. Increased capsaicin content in PFP resistant cells of chili peppers (Capsicum annuum L.). Plant Cell Rep. 8:617-620.

Stewart, Jr., C., M. Mazourek, G.M. Stellari, M. O’Connell, and M. Jahn. 2007. Genetic control of pungency in C. chinense via the Punl locus. J. Expt. Bot. 58:979-991.

Sung, Y., Y.Y. Chang, and N.L. Ting. 2005 Capsaicin biosynthesis in water-stressed hot pepper fruits. Bot. Bull. Acad. Sinica (Taiwan) 46:35-42.

Zamudio-Moreno, E. 2007. Dimerización enzimática de capsaicinoides por proteína enlazada iónicamente a pared de células de capsicum spp crecidas in vitro. TESE y CINVESTAV-IPN (Departamento de Biotecnología Y Bioingeniería). Master in Sciences Thesis. 